\title{
Prognosis of patients with systemic lupus erythematosus in the intensive care unit
}

Silvio Namendys-Silva, Miguel Reyes-Ruiz, Eduardo Rivero-Sigarroa and Guillermo Domínguez-Cherit

Secretaría de Salud, Instituto Nacional de Ciencias Médicas y Nutrición "Salvador Zubirán", Intensive Therapy Department, Ciudad de México, Mexico

\begin{abstract}
Introduction: Identification of risk factors for mortality has enabled improving the treatment of critically ill patients with systemic lupus erythematosus. Objective: To describe clinical characteristics and prognoses of critically ill patients with systemic lupus erythematosus admitted to an intensive care unit. Method: Prospective, observational cohort study. A total of 207 patients with systemic lupus erythematosus admitted between January 2011 and January 2016 were included. Results: During the study period, 3,215 critically ill patients were admitted to the intensive care unit, out of which 207 (6.4\%) were identified as having systemic lupus erythematosus after being evaluated by an intensivist. The multivariate analysis identified the presence of organ failure (cardiovascular, liver, neurological) and serum lactate levels $>2 \mathrm{mmoL} / \mathrm{L}$ at admission or within the first 24 hours of intensive care unit stay as the main factors associated with increased mortality. Conclusions: $A$ relevant observation was that neurological failure and liver failure were associated with higher mortality risk at 28 days, without reports similar to these findings being identified.
\end{abstract}

KEY WORDS: Lupus. Antiphospholipid syndrome. Intensive care.

\section{Introduction}

Systemic lupus erythematosus (SLE) is a rheumatologic polymorphic disease where there is autoimmunity in all organs and it is characterized by exacerbations and remissions. ${ }^{1}$ It is a pro-inflammatory pathology where the patient is predisposed to infections during the exacerbation states, which can cause life-threatening clinical conditions., ${ }^{2,3}$ On the other hand, immunosuppressive treatment can increase the risk of systemic complications. ${ }^{4}$

Although there are no precise statistical data, prevalence of SLE is high worldwide, with a trend to increase. ${ }^{5,6}$ In spite of the above, mortality has decreased in recent decades, probably owing to earlier diagnosis and higher availability of immunosuppressive treatments. ${ }^{7-9}$ In severely ill patients with SLE who require admission to an intensive care unit (ICU), cardiovascular failure remains one of the main risk factors for death.10,11 In some series, the following death predictors have been identified in critical patients with SLE: respiratory system infections, APACHE II high score, need for renal replacement therapy, use of mechanical ventilation and SLEDAI high score. ${ }^{12,13}$ The identification of risk factors for mortality has allowed to improve the treatment of critical patients with SLE. ${ }^{14,15}$ The purpose of the present work was to describe the clinical characteristics and prognosis of critically ill patients with LEG admitted to an ICU.

\section{Method}

Descriptive, analytical, observational study carried out at the ICU of Instituto Nacional de Ciencias Médicas y Nutrición "Salvador Zubirán", between January 2011 and January 2016. The UCI has 14 beds to take
Date of reception: 30-07-2017

Date of acceptance: 18-01-2018

DOI://dx.doi.org/10.24875/GMM.M18000173
Gac Med Mex. 2018;154:394-398

Contents available at PubMed www.gacetamedicademexico.com 
care of seriously ill patients and has the capability to provide advanced support such as invasive mechanical ventilation, hemodialysis and plasmapheresis. All severely ill patients with SLE, of either gender, older than 16 years, who remained in the ICU for more than 24 hours were included. Demographic and clinical data were obtained from the clinical record and the electronic file. The patients met the criteria for SLE upon ICU admission or were classified as having SLE during their stay at the ICU.

The following data were recorded: age, gender, time since SLE diagnosis, steroid dose at ICU admission, diagnosis for admission to the unit, days of stay in it, place of provenance, APACHE ${ }^{116}$ score and SOFA ${ }^{17}$ score upon ICU admission, as well as number of SOFA-defined organ failures..$^{18}$ In addition, the need for vasopressors, required dose, serum lactate at admission, $\mathrm{PaO} 2 / \mathrm{FiO} 2$ at admission to the $\mathrm{ICU}$, need for mechanical ventilation (MV) and reason, days of MV, creatinine level, platelet count and bilirubin levels were recorded. Additionally, the presence of clinical or serological secondary antiphospholipid syndrome (APS) and the score on the Glasgow Coma Scale (GCS) prior to receiving sedation, if required, were recorded. ${ }^{16-20}$ Mortality was recorded at 7 and 28 days of $\mathrm{UCl}$ discharge.

\section{Statistical analysis}

Descriptive statistics was used for data presentation and the Kolmogorov-Smirnov test was used to determine their distribution. Numerical variables were expressed as median and interquartile ranges, given that all continuous variables showed a non-parametric distribution; nominal variables were represented as numbers and percentages.

Cox univariate and multivariate regression analysis was used to identify factors related to mortality increase at 28 days. Variables with clinical relevance and those predictive of the primary endpoint in the univariate analysis were introduced in the final model. The results were expressed as hazard ratios with their respective $95 \%$ confidence intervals. Survival curves were estimated using the Kaplan-Meier method. Survival data were compared with the log-rank test. In all cases, a $p$-value $<0.05$ was considered to be statistically significant. For the processing of data, the statistical program SPSS 22.0 was used.

The present study adhered to the considerations formulated in the Declaration of Helsinki and its Tokyo amendment for biomedical research works in human
Table 1. General characteristics of 207 patients with systemic lupus erythematosus admitted to an intensive care unit

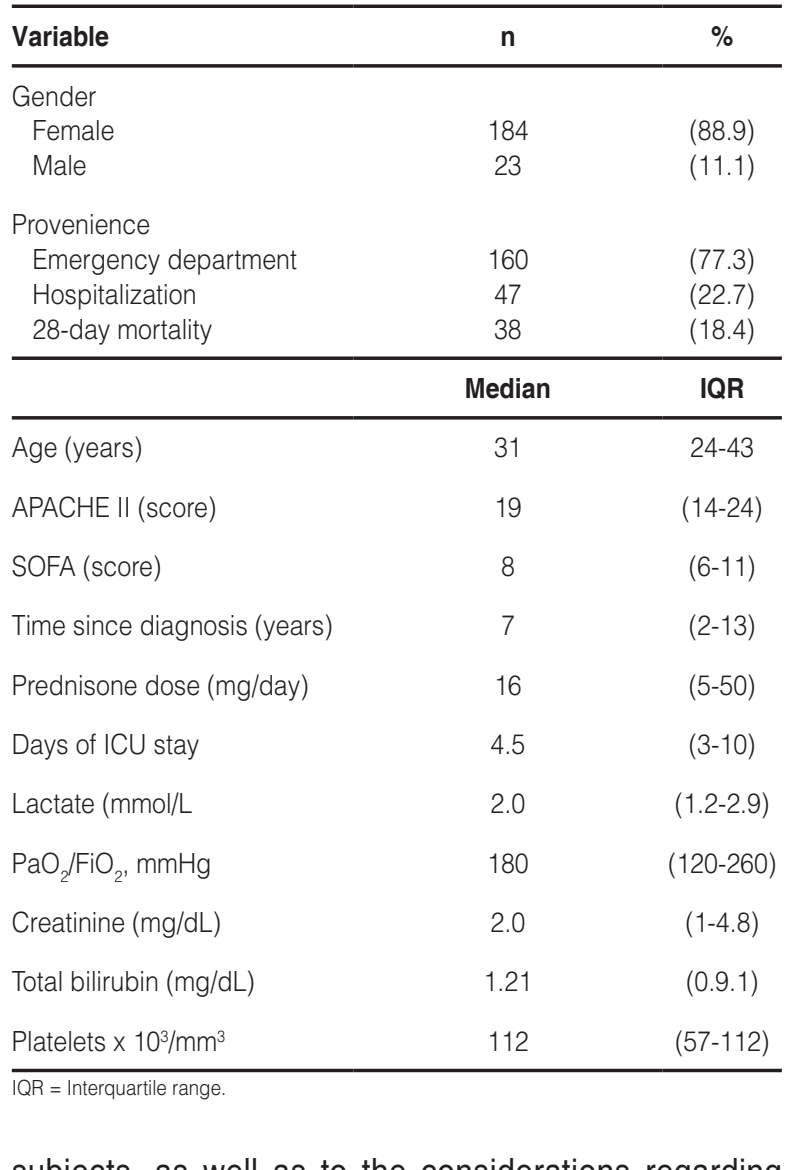

subjects, as well as to the considerations regarding research for health formulated in the General Statute of Health of the Mexican United States. Since this was an observational study, written informed consent from the patients was not necessary.

\section{Results}

During the study period, 3215 seriously ill patients were admitted to the ICU, among them 207 (6.4\%) with SLE after being evaluated by an intensivist. Median age was 31 years, and $88.9 \%$ were of the female gender. Median time since SLE diagnosis was 7 years. The characteristics of the patients included in the study are shown in Table 1.

A total of $74.4 \%$ of patients were admitted due to a medical problem: infectious (46.4\%), cardiovascular $(16.9 \%)$ and neurological (10.5\%) in nature. The most commonly observed organ failures were kidney $(71.5 \%)$, hematologic $(64.3 \%)$ and respiratory failure (62.8\%). MV was required by $77.8 \%$ of patients; mean duration was 6 days. Mortality was $18.4 \%$ (38/207). Mortality of patients with 4 or more organ failures was $39.7 \%$ (29/73). Table 2 shows the 
Table 2. Relationship between the number of organ failures and 28-day mortality in patients with systemic lupus erythematosus admitted to an intensive care unit

\begin{tabular}{lccccc}
\hline Failures & & & & \multicolumn{3}{c}{ Mortality } \\
\cline { 1 - 2 } \cline { 5 - 6 } Number & $\mathbf{n}$ & $\%$ & & $\mathbf{n}$ & $\%$ \\
\hline 0 & 2 & 1 & & 0 & 0 \\
1 & 34 & 16.4 & & 1 & 2.9 \\
2 & 41 & 19.8 & & 1 & 2.4 \\
3 & 57 & 27.5 & & 7 & 12.3 \\
4 & 46 & 22.2 & & 13 & 28.2 \\
5 & 23 & 11.1 & & 14 & 60.8 \\
6 & 4 & 1.9 & 2 & 50 \\
\hline
\end{tabular}

relationship between the number of organ failures and 28-day mortality.

Of the patients who experienced respiratory failure, $20(9.7 \%)$ had a diagnosis of diffuse pulmonary hemorrhage (DPH) and 14 met the criteria for acute respiratory distress syndrome (ARDS) (6.8\%). 28-day mortality of patients with respiratory failure was 28.6 $\%(4 / 20)$.

Tables 3 and 4 show detailed results of the univariate and multivariate analyses to identify the factors associated with mortality increase at 28 days. The factors associated with 28-day mortality increase were cardiovascular failure $(\mathrm{HR}=3.27,95 \% \mathrm{Cl}=1.41$ $7.54, p=0.005)$, liver failure $(H R=2.16,95 \%$ $\mathrm{Cl}=1.11-4.22, \mathrm{p}=0.024)$, neurological failure $(\mathrm{HR}=3.42,95 \% \mathrm{Cl}=1.75-6-68, \mathrm{p}<0.001)$ and serum lactate levels $(\mathrm{HR}=1.17,95 \% \mathrm{Cl}=1.06-1.29$, $p=0.002)$ (Table 4 and Figure 1).

\section{Discussion}

The main findings of the present study were:

- Mortality of severely ill patients with LEG admitted to the ICU was $18.4 \%$.

- The main factors associated with 28-day mortality increase were neurological, cardiovascular and liver failures.

- Lactate levels at ICU admission or during the first 24 hours of stay constitute a biomarker of risk for death in severely ill patients with SLE.

Different groups have reported mortality decreases in patients with SLE over the course of the last decade, which may be related to an improvement in SLE treatment and technological advances in intensive care, in addition to early admission to the ICU having
Table 3. Univariate analysis to identify factors related to 28-day mortality in patients with systemic lupus erythematosus admitted to an intensive care unit

\begin{tabular}{|c|c|c|c|c|}
\hline Variable & HR & $95 \% \mathrm{Cl}$ & $\stackrel{\infty}{-\infty}$ & $p$ \\
\hline Age (years) & 1.03 & $1.01-1.06$ & & 0.001 \\
\hline Male gender & 0.41 & $0.10-1.73$ & & 0.230 \\
\hline APACHE II & 1.11 & $1.07-1.16$ & & $<0.001$ \\
\hline SOFA & 1.37 & $1.25-1.51$ & $<$ & $<0.001$ \\
\hline Cardiovascular failure & 5.8 & $2.66-12.6$ & & $<0.001$ \\
\hline Lactate (mmol/L) & 1.28 & $1.17-1.39$ & & $<0.001$ \\
\hline Lactate $>2 \mathrm{mmol} / \mathrm{L}$ & 2.45 & $1.27-4.75$ & & 0.008 \\
\hline Respiratory failure & 1.69 & $0.82-3.48$ & & 0.154 \\
\hline $\mathrm{PaO}_{2} / \mathrm{FiO}_{2}(\mathrm{mmHg})$ & 0.99 & $0.99-1.0$ & & 0.104 \\
\hline Kidney failure & 1.12 & $0.54-2.32$ & & 0.741 \\
\hline Hematological failure & 2.66 & $1.17-6.04$ & & 0.019 \\
\hline Liver failure & 3.44 & $1.82-6.52$ & & $<0.001$ \\
\hline Neurological failure & 4.07 & $2.12-7.81$ & & $<0.001$ \\
\hline APS & 0.72 & $0.35-1.46$ & & 0.367 \\
\hline ARDS & 1.62 & $0.57-4.57$ & & 0.360 \\
\hline DPH & 0.48 & $0.11-2.0$ & & 0.317 \\
\hline
\end{tabular}

$\mathrm{HR}=$ Hazard ratio, APACHE = Acute Physiology and Chronic Health Evaluation, $\bigcirc$ SOFA = Sequential Organ Failure Assessment, APS = Anti-phospholipid syndrome ARDS $=$ Acute respiratory distress syndrome, $\mathrm{DPH}=$ Diffuse pulmonary hemorrhage

been internationally promoted with a lower number of organ failures. Overall mortality in the present work was lower than that reported by other centers. ${ }^{13,21} \mathrm{Du}$ mas et al..$^{11}$ reported a mortality rate of $20 \%$ in rheumatologic patients, similar to that found in the present work.

APACHE II and SOFA ${ }^{16-19}$ scores of have been associated with higher mortality in seriously ill patients with SLE. Our group ${ }^{10}$ reported that the APACHE II score was 19.7 during the first 24 hours of ICU stay, similar to that of the present report. Other authors have reported higher APACHE II scores and higher mortality. ${ }^{13}$

Few studies have used the SOFA score to determine if a patient with SLE is admitted or not to the ICU; in the present work, it was included and was identified as a risk factor for death. Other authors, ${ }^{11}$ in spite of not categorizing the SOFA scores by organ failures, have reported lower scores in comparison with the score in our group of patients with SLE (5 versus 8 points), which suggests that in the ICU of our center patients with larger number of organ failures or higher severity are admitted; however, in spite of this difference in the SOFA score, mortality was similar ( $21 \%$ versus $18.3 \%$ ). 

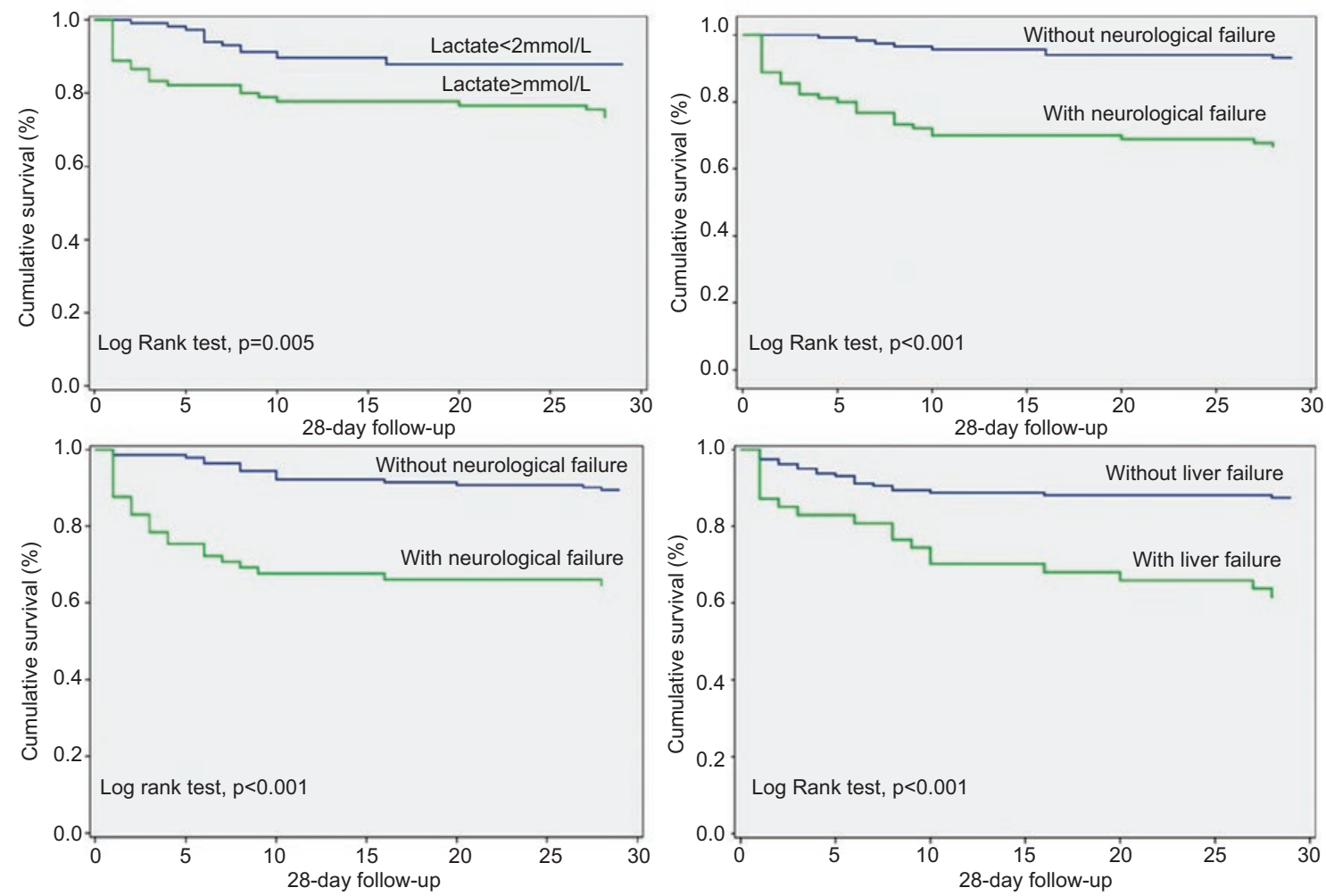

Figure 1. Survival curves according to 28-day mortality-associated factors in patients with systemic lupus erythematosus admitted to an intensive care unit.

Table 4. Multivariate analysis to identify factors related to 28-day mortality in patients with systemic lupus erythematosus admitted to an intensive care unit

\begin{tabular}{lccc}
\hline Variable & HR & $\mathbf{9 5} \% \mathbf{C l}$ & $\mathbf{p}$ \\
\hline Cardiovascular failure & 3.27 & $1.41-7.54$ & 0.005 \\
Liver failure & 2.16 & $1.11-4.22$ & 0.024 \\
Neurological failure & 3.42 & $1.75-6-68$ & $<0.001$ \\
Lactate $>$ 2 mmol/L & 1.17 & $1.06-1.29$ & 0.002 \\
\hline
\end{tabular}

$\mathrm{HR}=$ Hazard ratio.

\section{Conclusions}

When the number and type of organ failures patients were admitted with were assessed, similar results to those of other studies were found, ${ }^{10-13}$ with cardiovascular failure being one of the main risk factors for death. Although in our group of patients the organ failure with the highest prevalence was kidney failure, it had no impact on mortality. One relevant finding was that neurological failure and liver failure were associated with higher risk of death at 28 days; in this sense, there are no reports similar to our results. Neurological alterations of severely ill patients with sepsis, vascular events or epileptic states were the main causes of neurological involvement in our cohort. 22,23 Patients with SLE and neurological alteration have been described to have high mortality; ${ }^{24}$ therefore, they require surveillance in monitored areas in order to improve the prognosis. Finally, similar to reports by other authors, ${ }^{25,26}$ serum lactate level during the first 24 hours of $\mathrm{UCl}$ stay was associated with higher mortality.

The main limitation of the present study lied in that it was carried out in a single center with high concentration of patients with immune diseases.

\section{References}

1. David $P$, Munther A, Graham R. Systemic lupus erythematosus. Lancet. 2007:369:587-596

2. Navarra S, Leynes M. Infections in systemic lupus erythematosus. Lupus. 2010;19:1419-1424

3. Han BK, Bhatia R, Traisak P, Hunter K, Schorr C, Eid H, et at. Clinical presentations and outcomes of systemic lupus erythematosus patients with infection admitted to the intensive care unit. Lupus. 2013;22:690-696.

4. Ruiz-Irastorza G, Olivares N, Ruiz-Arruza I, Martinez-Berriotxoā A, Egurbide MV, Aguirre $\mathrm{C}$, et al. Predictors of major infections in systemic lupus erythematosus. Arthritis Res Ther. 2009;11:R109.

5. Pons-Estel GJ, Alarcón GS, Scofield L, Scofield L, Reinlib L, Cooper GS. Understanding the epidemiology and progression of Systemic Lupus Erythematosus. Semin Arthritis Rheum. 2010;39:257-268.

6. Danchemko N, Satia JA, Anthony MS. Epidemiology of systemic lupus erythematosus: a comparation of worldwide disease burden. Lupus. 2006;15:308-318.

7. Souza DC, Santo AH, Sato El. Mortality profile related to systemic lupus erythematous: a multiple cause-of-death analysis. J Rheumatol. 2012;39:496-503.

8. Fei Y, Shi X, Gan F, Li X, Zhang W, Li M, et al. Death causes and pathogens analysis of systemic lupus erythematosus during the past 26 years. Clin Rheumatol. 2014;33:57-63.

9. Zonana-Nacach A, Yañez P, Jiménez-Balderas FJ, Camargo-Coronel A Disease activity, damage and survival in Mexican patients with acute severe systemic lupus erythematosus. Lupus. 2007;16:997-1000. 
10. Namendys-Silva SA, Baltazar-Torres JA, Rivero-Sigarroa E, Fonseca-Lazcano JA, Montiel-López L, Domínguez-Cherit G. Prognostic factors in patients with systemic lupus erythematosus admitted to intensive care unit. Lupus. 2009;18:1252-1258.

11. Dumas G, Géri G, Montlahuc C, Chemam S, Dangers L, Brechot N, et al Outcomes in critically ill patients with systemic rheumatic disease: a multicenter study. Chest. 2015;148:927-935.

12. Quintero OL, Rojas-Villarraga A, Mantilla RD, Anaya JM. Autoimmune diseases in the intensive care unit. An update. Autoimmun Rev. 2013; 12:380-395.

13. Siripaitoon B. Lertwises S. Uea-areewongsa $P$, et al. A study of Tha patients with systemic lupus erythematosus in the medical intensive care unit: epidemiology and predictors of mortality. Lupus. 2015;24:98-106.

14. Mak A, Cheung M, Chiew H, Liu Y, Ho RC. Global trend of survival and damage of systemic lupus erythematous: meta-analisis and meta-regression of observational studies from the 1950s to 2000s. Semin Arthritis Rheum. 2012;41:830-839.

15. Camargo JF, Tobón GJ, Fonseca N, Diaz JL, Uribe M, Molina F, et al. Autoimmune rheumatic disease in the intensive care unit: experience from a tertiary referral hospital and review of the literature. Lupus. 2005; $14: 315-320$.

16. Knaus WA, Draper EA, Wagner DP, Zimmerman JE. APACHE II: A severity of disease classification system. Crit Care Med. 1985;13: 818-829.

17. Vincent JL, Moreno R, Takala J, Willatts S, De-Mendonça A, Bruining H, et al. The SOFA (Sepsis-related Organ Failure Assessment) score to describe organ dysfunction/failure. On behalf of the Working Group on
Sepsis-Related Problems of the European Society of Intensive Care Medicine. Intensive Care Med. 1996;22:707-710.

18. Ferreira FL, Bota DP, Bross A, Mélot C, Vincent, JL. Serial evaluation of the SOFA score to predict outcome in critically ill patients. JAMA. 2001;286:1754-1758.

19. ARDS Definition Task Force, Ranieri VM, Rubenfeld GD, Thompson BT, Ferguson ND, Caldwell E, et al. Acute respiratory distress syndrome: the Berlin Definition. JAMA. 2012;307:2526-2533.

20. Hess DR. Respiratory mechanics in mechanically ventilated patients. Respir Care. 2014;11:1773-1794.

21. Hsu CL, Chen KY, Yeh PS, Hsu YL, Chang HT, Shau WY, et al. Outcome and prognostic factors in critically ill patients with systemic lupus erythematosus: a retrospective study. Crit Care. 2005;9:R177-R183.

22. Kuroda Y. Neurocritical care update. J Intensive Care. 2016;4:36.

23. Iwashyna TJ, Ely EW, Smith DM, Langa KM. Long-term cognitive impairment and functional disability among survivors of severe sepsis. JAMA 2010;304:1787-1794.

24. Bhattacharyya S, Helfgott SM. Neurologic complications of systemic lupus erythematosus, Sjögren syndrome and rheumatoid arthritis. Semin Neurol. 2014;34:425-436.

25. Haas SA, Lange T, Saugel B, Petzoldt M, Fuhrmann V, Metschke M, et al. Severe hyperlactatemia, lactate clearance and mortality in unselected critically ill patients. Intensive Care Med. 2016;42:202-210.

26. Juneja D, Singh O, Dang R. Admission hyperlactatemia: causes, incidence, and impact on outcome of patients admitted in general medical intensive care unit. J Crit Care. 2011;26:316-320. 